\title{
Der Arzt und das e-
}

\section{Remo Osterwalder}

Dr. med., Vizepräsident der FMH, Departementsverantwortlicher Dienstleistungen und Berufsentwicklung

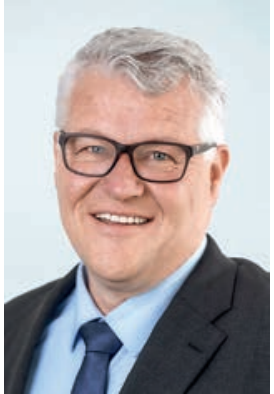

Das heutige Editorial widmet sich dem durchschnittlichen Arbeitstag eines Arztes / einer Ärztin aus der digitalen Perspektive. Die erste Wahrnehmung morgens ist das iPhone. Es weckt mich planmässig, je nach Programm anders. (Das lässt ja bis zu einer Woche im Voraus einstellen.) Beim Frühstück gehe ich nochmals die Agenda auf dem Laptop durch. Dieser ist direkt mit dem Server der Praxis verbunden und erlaubt mir so eine straffe Organisation der kommenden Stunden. Beim Verlassen des Hauses erhalte ich ein SMS aufs Handy, welche mich über die aktuelle Verkehrssituation bis zur Praxis informiert. Diese Unterstützung hat sich das Gerät selbst zugelegt, die Geo-App registriert meine Routinebewegungen. In der Praxis öffne ich mit dem Badge die Tür, was wiederum eine virtuelle Spur meines täglichen Lebens hinterlässt. Speziell auch, dass diese Zugangsberechtigung mit Namen, Zeit und Standort, beziehungsweise Tür, in den Niederlanden hinterlegt ist. Wer diese Daten wie nutzen könnte, entzieht sich meiner Kenntnis.

\section{Kurz aufs Internet - und bereits macht mich Werbung auf neue medizinische Geräte aufmerksam.}

Beim Einloggen auf dem Laptop hinterlasse ich wieder einen digitalen Abdruck. Nochmals kurz aufs Internet und siehe da, bereits macht mich Werbung auf neue medizinische Geräte aufmerksam. Längst schockiert mich das nicht mehr, habe ich doch gestern Abend eine entsprechende Suche im Internet durchgeführt. Ist doch zuvorkommend vom WWW, mich mit solchen Informationen $\mathrm{zu}$ bedienen (Achtung: Ironisch gemeint). Vor der ersten Konsultation telefoniere ich noch schnell via Fixnet. Wie ich kürzlich informiert wurde, nimmt mir die Telefongesellschaft einen Stimmabdruck ab. Soll wohl heissen, dass sie mich nun stimmlich als Kunden identifizieren kann - good vibrations?

Und nun geht's los: Während mehrerer Stunden füttere ich meinen Computer mit Informationen über den
Gesundheitszustand meiner Patienten. Diese Daten bleiben auf dem Praxisserver und sind vertraulich. Eine Situation, die sich spätestens dann ändern wird, wenn die ersten Patienten ein elektronisches Dossier verlangen. Hoffe, dass meine administrative Arbeit dadurch nicht noch mehr zunimmt. Da die Daten dann auch ausser Haus gehen, werde ich mein Personal instruieren, die Dokumentenablage zwei oder besser drei Mal zu kontrollieren, damit bloss kein Dokument beim falschen Patienten abgelegt wird. Das bedeutet dann wohl, dass ich mehr Personal einstellen muss.

\section{Patientendaten bleiben auf dem Praxisserver.} Was sich ändern wird, sobald die ersten Patienten ein e-Dossier verlangen.

Da ich am Nachmittag im Spital arbeite, verlasse ich die Praxis um 12 Uhr und erhalte prompt die freundliche SMS über den Verkehrszustand für die 20-minütige Autofahrt. Und auch dort das Prozedere mit Badge und Einloggen. Zuerst steht die Diskussion einer genetischen Analyse auf der Agenda. Nun gilt es herauszufinden, ob der Patient bereit ist, an einer internationalen Studie teilzunehmen. Dazu müsste ich seine Angaben an eine andere Institution weiterleiten, wofür ich sein Einverständnis benötige. Was bedingt, dass ich ihn über die Weiterverwendung seiner Daten präzise informiere. Nebenbei, die zentrale Datenverwaltung für diese Studie liegt in Brüssel, und das Studienteam verteilt sich auf fünf weitere Institute rund um den Globus.

Um 18 Uhr verlasse ich die Klinik, natürlich korrekt protokolliert. Ich muss mich beeilen, um rechtzeitig ins Einkaufscenter zu gelangen. Da ich keine Zeit hatte, Bargeld zu beziehen, bezahle ich mit dem Handy über PayPal, was schon praktisch ist. Übrigens, ab 2018 wird es im EU-Raum bei dieser Bezahl-App eine Änderung geben. Ab dann erhält sie, also mein Handy, «endlich» direkten Zugang auf mein Bankkonto. Ich bin gespannt, wie es weitergeht. Hoffentlich werde ich nicht eines Tages wegen des Handys meinen Job verlieren, da es diese Funktion auch noch übernommen hat. 